\title{
Projeto de educação ambiental em escolas na cidade de Currais Novos (Rio Grande do Norte, Brasil) como facilitador na relação da educação ambiental e o turismo
}

\author{
Environmental education project in schools of Currais Novos (Rio Grande do Norte, \\ Brazil) as a facilitator in the relationship between environmental education and tourism
}

\author{
Mayara Ferreira de Farias (FARIAS, M. F. de) ${ }^{*}$ \\ Kettrin Farias Bem Maracajá (MARACAJÁ, K. F. B.) ${ }^{* *}$
}

\begin{abstract}
RESUMO - Meio ambiente consiste em um dos assuntos mais discutidos na atualidade, tendo em vista novas preocupações e perspectivas positivas diante da utilização de um desenvolvimento sustentável em diversas atividades realizadas. Nesta perspectiva se encontra a atividade turística, que aliada à educação ambiental pode reverter alguns acontecimentos da atualidade. O presente trabalho tem como objetivo apresentar os resultados do projeto de extensão "Educação ambiental e conscientização da população", desenvolvido durante o ano de 2010 em 11 escolas municipais e estaduais na cidade de Currais Novos (Rio Grande do Norte, Brasil), o qual atendeu a 1.312 alunos das séries do $1^{\circ}$ ao $5^{\circ}$ ano. O projeto esteve vinculado à Universidade Federal do Rio Grande do Norte, sendo financiado pelo REUNI - Programa de Apoio a Planos de Reestruturação e Expansão das Universidades Federais. Foram abordadas questões sobre Educação, Escolas no processo educacional, Turismo, Educação Ambiental no Turismo e Educação Ambiental na escola. A metodologia utilizada foi a utilização de palestras, observação sobre a percepção e participação das crianças durante e após as mesmas. Em linhas gerais, os resultados foram satisfatórios e imediatos à realização das palestras nas escolas.
\end{abstract}

Palavras-chave: Educação Ambiental; Escolas; Turismo.

ABSTRACT - Environment is one of the most discussed topics nowadays, in view of new concerns and positive prospects on the use of sustainable development in several activities. In this perspective is the tourism activity, which linked to environmental education can reverse some current events. This paper aims to present the results of the extension project named "Environmental education and public awareness" developed during the year 2010 in 11 state and municipal schools in the city of Currais Novos (Rio Grande do Norte, Brazil), which attended 1,312 students from 1st to 5th grade of junior high. The project was linked to the Federal University of Rio Grande do Norte, and it was funded by REUNI - Support Program for the Restructuring and Expansion of Federal Universities. It was discussed issues related to Education, Schools in the educational process, Tourism, Tourism and Environmental Education and Environmental Education in the school. The methodology used was lectures, observation on the perception and participation of children during and after the lectures. In general, the results were satisfactory and the immediate after the implementation of the lectures in the schools.

Key words: Environmental Education; Schools; Tourism.

\footnotetext{
Acadêmica de Turismo da Universidade Federal do Rio Grande do Norte - UFRN. Bolsista do projeto de extensão "Educação Ambiental e a conscientização da população". Endereço para correspondência: Rua Getúlio Vargas, número 42 (Centro). CEP: 59220-000 - Coronel Ezequiel - Rio Grande do Norte (Brasil). Telefone para contato: (84) 8889-3215. E-mail: mayarafarias23@ hotmail.com

** Graduação em Turismo (Bacharelado) pelo Instituto de Educação Superior da Paraíba - IESP. Mestrado em Administração pela Universidade Estadual do Ceará - UECE. Doutorado em andamento (Recursos Naturais na Universidade Federal de Campina Grande - UFCG). Docente efetiva do curso de Turismo na UFRN (Currais Novos). Endereço para correspondência: Rua Felipe Guerra, 510, ap. 604. CEP: 59300-000 - Caicó - Rio Grande do Norte (Brasil). Telefone para contato: (84) 9921-9563. E-mail: kettrinfarias@ hotmail.com
} 


\section{INTRODUÇÃO}

A globalização trouxe consigo uma série de mudanças que afetaram direta e indiretamente a vida de todos. As ideologias mudaram, as vontades mudaram, as localidades mudaram e, especialmente, as pessoas mudaram. Mudaram sua maneira de ver o mundo, de querer que existam cada vez mais coisas que venham a atender suas necessidades básicas e supérfluas a ponto de descartarem com uma facilidade e em um tempo significativamente pequeno, a ponto de provocar, cada vez mais, um acúmulo de objetos e substâncias indesejáveis, na maioria das vezes, poluindo o meio ambiente sem qualquer consciência de que tudo provoca uma reação a esta ação.

Nesta perspectiva, pode-se inferir que se necessita cada vez mais de pessoas que procurem, de alguma forma, conscientizar e sensibilizar a todos sobre as questões ambientais, principalmente ao que diz respeito à preservação e conservação da natureza para que outras pessoas possam usufruir da mesma futuramente.

A educação ambiental, por sua vez, consiste em um dos principais aliados a esta procura por possibilitar mostrar a todos o que deve e o que não deve ser feito diante da realidade atual. A educação, adaptada aos novos momentos, com suas muitas facetas, tem um papel importante nesse contexto, pois é ela quem tem o poder de mudar a mentalidade do indivíduo e, assim, construir a tolerância e erradicar a semente do individualismo e da violência. A promoção da consciência ecológica, da paz, da solidariedade e do coletivismo são atribuições suas e qualificantes da sua importância.

A problemática do trabalho se deu no sentido mostrar qual o papel da Educação Ambiental nas escolas municipais e estaduais de Currais Novos (Rio Grande do Norte, Brasil) como forma de incentivar as crianças a promoverem um futuro melhor para o planeta.

Justificou-se a realização do projeto, "Educação Ambiental nas escolas", pela oportunidade de conscientizar as crianças sobre a importância da educação ambiental na vida das pessoas despertando nelas a sensibilidade, o prazer em fazer algo pelo meio ambiente e ajudar assim, o mundo. No qual o público-alvo se concentrou em escolas estaduais e municipais da cidade de Currais Novos. Para realização deste trabalho disponibilizou-se de material didático, como livros, materiais retirados da internet, além de trabalhos realizados em algumas escolas de Currais Novos. 
Nesta perspectiva se incluiu a educação ambiental nas escolas, foco principal do Projeto "Educação Ambiental na comunidade" na cidade de Currais Novos, com objetivo principal de sensibilizar e conscientizar crianças de escolas estaduais e municipais para que o efeito multiplicador de proteção e conservação do meio ambiente ocorra de forma mais ampla e efetiva.

Para entender a real importância do projeto e de seus resultados, destacam-se, no presente trabalho, conceitos e considerações sobre educação, turismo, educação ambiental e ambiente escolar, com ênfase na educação voltada para crianças, que por sua vez, difundirão através das relações sociais e familiares existentes, a importância de preservar o meio ambiente para que vidas futuras possam usufruir o que se pode usufruir atualmente.

\section{A ESCOLA ATUANDO NA FORMAÇÃO DA OPINIÃO CONSCIENTE}

A escola é a formação básica de um ser humano, sem ela é difícil pensar nesta constatação. Entende-se que a educação engloba os processos de ensinar e aprender. É um fenômeno observado em qualquer sociedade e nos grupos constitutivos destas, responsável pela sua manutenção e perpetuação a partir da transposição, às gerações que se seguem, dos modos culturais de ser, estar e agir necessários à convivência e ao ajustamento de um membro no seu grupo ou sociedade.

Quem estuda tem mais acesso às oportunidades e ferramentas para disputas sociais. Além do mais, a permanência dos jovens na escola permite que eles fiquem mais tempo longe da violência. Indivíduos educados conhecem seus direitos, seus deveres, seus valores, se empregam e geram riquezas para a coletividade, para o país.

Os novos momentos são da informação e da tecnologia. Como nunca antes visto na história do mundo, o indivíduo que pretende se manter atualizado se vê em meio a um turbilhão de informações.

A educação convencional de outrora, centrada na escola, já é retrógrada e retarda o desenvolvimento de uma nova educação. O mundo vive um momento de desequilíbrio, em meio a guerras, destruição ambiental, exposição a drogas e violência generalizada. Apesar da crise, a educação se apresenta com múltiplos leques para a sua construção. Existe a internet (inclusão digital) e os tradicionais meios de comunicação que trazem uma quantidade 
imensurável de informação, seja esta útil ou não. Sendo assim, a educação é importante, uma vez que ensinar e aprender não se encerra nunca, daí, entende-se que a educação torna-se essencial para toda a sociedade.

Atualmente a educação está pautada nas diretrizes dos Referenciais Curriculares para Educação Infantil (RCNEI), Parâmetros Curriculares Nacionais (PCN's) para o Ensino Fundamental onde foram elaborados "com a intenção de ampliar e aprofundar um debate educacional que [...] dê origem a uma transformação positiva no sistema educacional brasileiro" (BRASIL, 1998, p. 8).

Os PCN's prevêem um processo progressivo para sua aplicação, como base para a atuação do professor em sala de aula. Segundo os documentos introdutórios, os Parâmetros deveriam ser utilizados progressivamente para subsidiar: as ações do MEC para o ensino fundamental; as revisões ou adaptações curriculares desenvolvidas pelas secretarias de educação, no âmbito dos estados e municípios; a elaboração do projeto educativo (proposta pedagógica) de cada escola, construído num processo dinâmico de discussão, envolvendo toda a equipe. E só então, no quarto e último nível de concretização, caberia ao professor a realização da proposta curricular na sala de aula.

Cada escola pode e deve, portanto, elaborar sua própria proposta pedagógica. Se construída de forma participativa e compromissada - não se revestindo apenas de um caráter burocrático - deve decidir como utilizar os recursos humanos e materiais disponíveis de modo a atender às necessidades específicas de seu alunado.

A proposta pedagógica é, pois, o espaço ideal para definir o melhor modo de encaminhar o trabalho de arte na escola, fazendo uso da autonomia prevista na Lei de Diretrizes e Bases da Educação - LDB (BRASIL, 1996) e nas Diretrizes Curriculares, e atendendo à flexibilidade da proposta dos PCN's proporcionando as condições necessárias para uma prática pedagógica de qualidade

A legislação brasileira que regulamenta a Educação está contida nos textos de (BRASIL, 1996) pautada nos princípios presentes na Constituição. Baseada no princípio do direito universal à educação para todos, onde trouxe diversas mudanças em relação às anteriores, como a inclusão da educação infantil (creches e pré-escolas) como primeira etapa da educação básica.

Geralmente, as leis tratam de assuntos técnicos, administrativos e burocráticos. É difícil imaginar-se uma "lei pedagógica", até porque pedagogia combina mais com princípios 
do que com leis. No entanto, a LDB tem um forte componente pedagógico, se considerar pedagogia enquanto ciência da instrução e da educação e não método.

Nesse sentido, há várias previsões legais que se dirigem ao administrativo, mas que implicam, obrigatoriamente, o pedagógico. A LDB já se inicia afirmando que a educação abrange os processos formativos que se desenvolvem em vários lugares, um dos quais é a escola. No Artigo $1^{\circ}$ afirma-se que a educação abrange os processos formativos que se desenvolvem na vida familiar, na convivência humana, no trabalho, nas instituições de ensino e pesquisa, nos movimentos sociais e organizações da sociedade civil e nas manifestações culturais (BRASIL, 1996).

Pode-se perceber uma clara opção pela formação, prevalecendo esta sobre a informação e que os professores não podem desconhecer nos seus planejamentos. Mais à frente (art. 24, V), quando a lei vai tratar da verificação do rendimento escolar, afirma-se ainda, que os aspectos qualitativos devam prevalecer sobre os quantitativos; ou seja, quantidade é importante, mas qualidade é mais importante.

A escola tem, pois, papel fundamental na transmissão do conhecimento consciente através de novas ferramentas, sejam elas a "educação participativa de pais de alunos" e a "educação ambiental voltada à sensibilização das gerações atuais e futuras". Através do conhecimento obtido através da aplicação e conhecimentos dos conceitos que envolvem novas metodologias de ensino e que inserem em sua carga horária de aula esta preocupação com o meio ambiente é, em uma perspectiva otimista, ponto inicial para as mudanças ocorrerem.

\section{SENSIBILIZAÇÃO AMBIENTAL NO AMBIENTE ESCOLAR}

Sensibilização significa mais do que parece ser a palavra. Muitos se confundem com os conceitos de conscientização e sensibilização, o que não devia ocorrer. Apesar de ambos os conceitos serem importantes, cabe ressaltar que conscientizar consiste em mostrar algo ou algum conceito sobre algo de forma a convencer a fazer o que se conhece como certo, tendo a pessoa que recebe estas informações uma opinião já formada sobre, podendo ou não mudar sua opinião. Sensibilizar, por sua vez, consiste em ensinar e transmitir algo novo, de forma que possibilita maior aceitação por parte de quem as recebe. 
Diante disso, ressalta-se que o projeto optou por trabalhar tanto a conscientização ambiental quanto, e principalmente, a sensibilização de crianças em escolas estaduais e municipais, tendo como expectativa uma maior aceitação e inserção dos ensinamentos voltados ao meio ambiente em suas vidas cotidianas.

Por educação entende-se que é através dela que se ganha personalidade para valorizar escolhas, ler o mundo, ampliar conhecimentos e filtrar com mais clareza as informações recebidas. Ela é relevante para a construção da cidadania além de ser uma espécie de introdução às relações de convivência.

Destaca-se, neste contexto, que a educação ambiental tem como um de seus objetivos formar cidadãos conscientes de sua relação com a natureza e com seu habitat, onde, independentemente da metodologia, deve primar pela formação de pessoas conscientes de seu papel e de sua relação com o meio ambiente de modo a primarem pela sustentabilidade, através do uso racional dos recursos naturais, para que tanto esta quanto as futuras gerações possam também deles usufruir, (NEIMAN; RABINOVICI 2002).

Parafraseando Gould (2004), a educação ambiental reúne o ponto de vista dos sujeitos sociais permitindo o estabelecimento de uma prática pedagógica contextualizada e crítica, apontando os problemas estruturais da sociedade, as causas do baixo padrão qualitativo da vida das pessoas e da utilização do patrimônio natural como uma mercadoria e uma externalidade em relação aos seres humanos. É através da atuação coletiva e individual, interferindo no funcionamento excludente e desigual das economias capitalistas, que os grupos sociais marginalizados podem ampliar a democracia e a cidadania. Intervindo, pois, no processo de exclusão social e de degradação das bases vitais do planeta, com novos padrões culturais cujos valores façam a população repensar na natureza.

A educação consiste no processo de desenvolvimento da capacidade física, intelectual e moral do ser humano. Sendo assim, o processo educacional que tem como elementos consagrados o professor, o aluno, o sistema gestor e a família, institucionalizados na escola necessita de constantes ajustamentos à realidade externa, a fim de cumprir o seu papel na sociedade.

A educação informal é anterior à educação formal, sistematizada por isso se faz necessário valorizar e cultuar estes conhecimentos que formam e sustentam o ser humano, servindo de base para o desenvolvimento de uma educação sistematizada mais eficiente, devido a sua adequação à realidade. 
Nessa perspectiva, para que a escola como uma instituição social, possa participar desse processo de desenvolvimento e transformação, necessita revisar e redefinir papéis vigentes, a fim de adaptar-se a novas exigências sociais, transformando a educação escolar em um dos instrumentos de desenvolvimento individual, social e econômico.

A escola de um futuro próximo deverá servir como um centro de troca de conhecimentos, pois o docente não dará ênfase ao conteúdo e à aquisição de conhecimentos. A ênfase será centrada no "aprender a aprender" e será proporcionada uma abertura a novos conceitos, com a participação ativa do discente opinando, e até discordando, com críticas construtivas àquilo que está sendo trabalhado.

O papel fundamental da educação no desenvolvimento das pessoas e das sociedades amplia-se ainda mais no despertar do futuro e aponta para a necessidade de se construir uma escola voltada para a formação de cidadãos (BRASIL, 1998).

$\mathrm{Na}$ escola, durante processos de socialização, a criança tem a oportunidade de desenvolver a sua identidade e autonomia. Interagindo com os colegas se dá a ampliação de laços afetivos que as crianças podem estabelecer com as outras crianças e com os adultos. Isso poderá contribuir para o reconhecimento do outro e para a constatação das diferenças entre as pessoas; diferenças essas, que podem ser aproveitadas para o enriquecimento de si próprias.

Acredita-se, pois, que o principal papel da escola é o desenvolvimento integral do ser humano, devendo considerá-lo em suas várias dimensões: afetiva, ou seja, nas relações com o meio, com os outros com quem convive; cognitiva, construindo conhecimentos por meio de trocas com parceiros mais e menos experientes e do contato com o conhecimento historicamente construído pela humanidade; social, frequentando não só a escola como também outros espaços de interação como praças, clubes, festas populares, espaços religiosos, cinemas e outras instituições culturais; e finalmente na dimensão psicológica, atendendo suas necessidades básicas como higiene, alimentação, moradia, sono, além de espaço para existência de carinho, atenção, respeito aos seus direitos (BRASIL, 2005).

A criança bem atendida, considerada um cidadão, enquanto cresce se depara com fenômenos, fatos e objetos do mundo; pergunta, reúne informações, organiza explicações e arrisca respostas.

Desse modo, ocorrem mudanças fundamentais no seu modo de conceber a vida, a natureza e a cultura. Além de promover a educação da criança, mostrando o correto, muitas vezes a escola terá que propiciar situações para que os pais reflitam sobre seus papéis e 
atribuições, tendo em vista que seus filhos permanecem mais tempo com eles do que na escola.

\section{TURISMO COMO ATIVIDADE EMERGENTE}

O turismo, atividade cultural, econômica, política e essencialmente social, consiste em um movimento de pessoas que saem dos seus locais de residências, de acordo com o seus desejos, utilizando-se de seu tempo livre a conhecer lugares sem desempenhar nenhuma função remunerada. Sendo uma atividade que envolve tempo, dinheiro, pessoas, empresas e prestadores de serviços com a finalidade de atender a necessidade dos viajantes, como Hotéis, Pousadas, Agências de Viagens, Restaurantes, entre outros. Cada parte tem a sua função e todas elas são muito importantes.

Além disso, o turismo é uma grande fonte de emprego e renda para uma localidade, envolvendo os mais diversos profissionais. O sucesso dessa atividade depende não só das belezas de um lugar, mas, principalmente, de uma prestação de serviços adequada, da qualidade desses serviços e da hospitalidade de todos os envolvidos.

O deslocamento de pessoas além de provocar a geração de vários empregos diretos e indiretos, contribuiu também para ampliar o universo intelectual do turista, a partir do intercâmbio social e cultural que esta atividade pode possibilitar.

As pessoas viajam, proporcionando motivações para o crescimento e desenvolvimento do turismo. Segundo Andrade (1992, p. 38) o turismo pode ser entendidocomo um "Complexo de atividades e serviços relacionados aos deslocamentos, alojamentos, alimentação, circulação de produtos típicos, atividades relacionadas aos movimentos culturais, visitas, lazer e entretenimento".

Entretanto, vale observar que as viagens acontecem devido às motivações sejam de negócios, de intercâmbios culturais, de saúde, de eventos, de lazer etc. Dentro dessa perspectiva, o turismo pode ser considerado um sistema, pois os vários serviços disponíveis aos turistas precisam funcionar juntos, como os órgãos de um corpo, para que o visitante seja bem recebido e saia satisfeito ao final da sua viagem. 
Turismo é um movimento de pessoas que saem dos seus locais de residências, viajando para outros lugares, de acordo com o seu gosto e o tempo que cada um tem disponível para realizar tais viagens.

Parafraseando Beni (2007), o turismo traz também alguns impactos para um lugar, impactos estes que podem ser positivos ou negativos. Dentre os positivos o supracitado autor destaca a geração de emprego e renda, por meio do desenvolvimento de equipamentos que objetivam receber pessoas, como pousadas, restaurantes e outros empreendimentos que visem também o bem-estar de todos; a valorização dos costumes e da cultura de um local, baseada no desenvolvimento sustentável da localidade, pois muitos turistas saem de suas residências em busca do "novo".

A atividade turística utiliza o meio ambiente como atrativo, no qual pode-se destacar alguns pontos negativos como os impactos causados ao Meio Ambiente, aumento dos preços, poluição etc. A diminuição dos impactos negativos, por sua vez, pode ser feita a partir do momento em que moradores e autoridades locais trabalhem unidos, de forma responsável e consciente.

É nesta perspectiva, do conflito entre turismo e conservação do meio ambiente, que surge o conceito de desenvolvimento sustentável. Esse desenvolvimento representa uma tentativa de busca de qualidade de vida para a sociedade atual e gerações vindouras, e um desenvolvimento sócio-econômico equitativo.

Entre outras ações voltadas para solucionar ou minimizar a crise ambiental, a educação ambiental é vista como uma alternativa para diminuir o distanciamento existente entre apropriação da natureza e degradação ambiental, possibilitando que a atividade turística, por sua vez, possa continuar a existir, tendo como premissa que o turismo necessita do espaço para que sejam realizadas as mais variadas atividades envolvidas no fenômeno.

\section{EDUCAÇÃO AMBIENTAL E A RELAÇÃO COM O TURISMO}

A temática sobre educação ambiental tem crescido de forma bastante relevante no Brasil, devido à área de meio ambiente ter sido incluída nos Parâmetros Curriculares Nacionais - PCNs, focando a pedagogia "no desenvolvimento de atitudes e posturas éticas e, 
no domínio de procedimentos, mais do que na aprendizagem de conceitos" (BRASIL, 1998, p. 201).

Com isso, muitos professores começaram a desenvolver a educação ambiental em suas salas de aula utilizando as questões ambientais como exemplos para identificar a degradação ambiental e o esgotamento dos recursos naturais disponíveis no planeta.

Para Tomazello e Ferreira (2001), é difícil analisar e avaliar projetos que objetivam desenvolver a educação ambiental, devido à abrangência dos temas e objetivos, pois, para muitos, educar ambientalmente é educar a partir da concepção de uma realidade complexa, isto é, em todos os elementos constituintes do ambiente estão em interação.

Quando relacionada ao turismo, a avaliação de um projeto de educação ambiental torna-se particularmente difícil, pois os resultados não têm uma relação direta com uma atividade ou estudo sobre o tema (TOMAZELLO; FERREIRA, 2001).

Isto significa que, devido o turismo ser uma atividade que engloba vários temas e setores, é praticamente impossível limitar apenas um tema para desenvolver ações de educação ambiental, já que o turismo utiliza vários recursos disponíveis no meio ambiente para acontecer, seja de forma direta, como ocorre na Amazônia, ou de forma indireta, quando acontece no meio urbano, mas, porém, precisa que uma localidade disponibilize, basicamente, de água tratada para consumo humano e saneamento básico para evitar a poluição de rios e açudes como também a proliferação de doenças na própria comunidade receptora, dentre outros aspectos relacionados à infraestrutura básica.

Para a Organização das Nações Unidas para a Educação - UNESCO (1987):

A educação ambiental é um processo permanente no qual os indivíduos e a comunidade tomam consciência do seu meio ambiente e adquirem conhecimentos, habilidades, experiências, valores e a determinação que os tornam capazes de agir, individual ou coletivamente, na busca de soluções para os problemas ambientais, presentes e futuros.

Segundo Tomazello e Ferreira (2001), estas questões ambientais foram elaboradas e discutidas na publicação de estudos e realização de eventos, com destaque para o relatório 
"Limites do Crescimento", publicado em 1972; a "Conferência de Estocolmo sobre Meio Ambiente", também realizada em 1972 e a "Rio - 92"3.

É relativamente atual a preocupação que se tem em relação à problemática do planeta, tanto que o conceito de sustentabilidade começou a ser discutido, oficialmente, no século passado. Para Ruschmann (1997) a educação para o turismo ambiental deverá ser desenvolvida por meio de programas não-formais, convidando o "cidadão-turista" a uma participação consciente na proteção do meio ambiente não apenas durante as férias, mas também no cotidiano e no local de residência permanente.

Com o advento da tecnologia, que se renova diariamente, há também o aumento da industrialização, que resulta no aumento do processo de produção de materiais e equipamentos dos mais diversos setores da economia, e, em conseqüência disso, aumenta o consumismo.

Tal fato contribui significadamente para o processo de crescimento populacional nos grandes centros, a tal problemática "urbanização". Problemática devido à falta de planejamento, pois as pessoas procuram grandes centros com o objetivo de melhorar de vida, mas acabam por piorar suas vidas e a de outras pessoas, porque algumas cidades crescem desordenadamente, e os recursos disponíveis, como água tratada, energia elétrica e até mesmo o saneamento básico, não comportam o número de indivíduos. Isso faz com que aumente também o número de comunidades pobres (favelas) nas encostas de rios, que utilizam a água tanto para consumo humano como para despejo de resíduos sólidos e líquidos.

É neste contexto que deve ser inserida a educação ambiental, pois é a partir dos conceitos que ela defende que as pessoas irão saber o risco que tem poluir e contaminar os recursos naturais do planeta, pensar na água como um recurso esgotável, assim como saber que a poluição do ar é conseqüência do próprio homem que não consegue respeitar os limites do planeta no qual vive.

Dias (2003) afirma que não se pode negar que o impacto do turismo sobre o meio ambiente é inevitável, então o que se pode fazer é manter a atividade dentro dos limites

\footnotetext{
${ }^{1}$ Relatório que discutia os limites de exploração e da conservação do planeta.

${ }^{2}$ Relatório que influenciou as nações a estruturarem seus órgãos ambientais e estabeleceu legislações que tinham como objetivo controlar a poluição ambiental e os resíduos perigosos, buscando garantir a qualidade de vida, o bem estar da humanidade.

${ }^{3}$ Momento no qual se defendeu a questão ambiental como uma preocupação global, sendo elaborado um documento intitulado de "Agenda 2l", o qual estabelecia compromissos e intenções para a preservação e melhoria da qualidade ambiental, visando a sustentabilidade do planeta.
} 
aceitáveis, para que não coloque em risco o meio ambiente, causando danos irreversíveis, assim os visitantes poderão usufruir melhor dos locais em que ela ocorre. $\mathrm{O}$ turismo não é o único vilão deste processo de modificação ambiental, pois existem outros processos econômicos que também contribuem para as mudanças ambientais ocorridas nos destinos turísticos.

Com isso, pode-se inferir que a relação entre turismo e meio ambiente é que o turismo utiliza a paisagem e a transforma em produto para ser consumido. Exemplo disso é o caso de Bonito, localizado no Mato Grosso do Sul (MS), onde o marketing para a venda do lugar como destino turístico utiliza da natureza, em suas piscinas naturais, cavernas, espécies raras e em extinção tanto da fauna como da flora, entre tantos outros atrativos disponíveis no lugar.

Não é que esta prática seja errônea, pelo contrário, quando a atividade turística é planejada, ela pode ser de grande influência para sensibilizar as pessoas sobre a questão ambiental.

Porém à medida que a humanidade aumenta sua capacidade de intervir na natureza para satisfação de desejos crescentes dos empresários e gestores públicos em melhor atender aos turistas ou visitantes, surgem tensões e conflitos quanto ao uso do espaço e dos recursos em função da tecnologia disponível.

O surgimento da sociedade capitalista, por sua vez, contribuiu para o início de um novo período, onde as pessoas buscavam fugir da vida difícil de algumas cidades e procuravam viajar para o campo, fazer caminhadas na beira do mar e excursões, buscando sempre o bem-estar que determinada localidade disponibilizasse, mas não se preocupando com os impactos, na maioria das vezes negativos, que o número de pessoas poderiam gerar em um determinado ecossistema.

O turismo, apesar de ser uma atividade que gera fontes de renda para a economia de uma localidade, necessita que os órgãos responsáveis pelo desenvolvimento dessa atividade identifiquem que não basta preparar e/ou capacitar os locais a serem visitados, mas também as pessoas que viajam para conhecer os locais, já que estas nem sempre possuem uma formação adequada, e, portanto, não saberão como respeitar a natureza.

A educação ambiental tem como base o desenvolvimento sustentável, e, de forma mais abrangente, volta-se para a prática do turismo sustentável, que visa à melhoria da qualidade de vida da comunidade receptora e oferece aos visitantes uma experiência enriquecedora, além 
de manter a qualidade do meio ambiente do qual, todos dependem. Segundo Cintra (2008, p. 930):

\begin{abstract}
Esse processo educativo de Conscientização Turística deve ter uma abordagem interdisciplinar e multidisciplinar, interagindo com todas as demais disciplinas escolares, uma vez que a Educação Ambiental tem relação com a realidade e adota a abordagem que considera os aspectos que compõem a questão ambiental, sóciocultural, político e outros sendo catalisadora de uma educação para a cidadania consciente, conduzindo a uma possível melhora do ambiente local/global e na qualidade da vida humana.
\end{abstract}

Porém, para que esta idéia de sustentabilidade ocorra é necessário que as pessoas tomem consciência e se sensibilizem sobre o que deve ser feito para preservar o meio ambiente. É nesse sentido que se pode inserir o papel fundamental da escola, principalmente as de ensino fundamental I, pois este nível escolar é um dos principais responsáveis pela educação e formação do cidadão, isto quer dizer que é nessa faixa etária que a criança começa a desenvolver sua personalidade, através da aquisição de conhecimentos para a elaboração consciente de seus princípios enquanto ser humano, os quais só irão se aperfeiçoar com o passar dos anos. Dias (2003, p. 178) afirma que, quando o assunto está relacionado a turismo sustentável e meio ambiente:

Um primeiro passo é considerar que as escolas têm um papel fundamental na modificação dos padrões de comportamento e consumo das crianças e dos jovens, com intuito de torná-los agentes ativos no processo de obter melhor qualidade de vida e adequado relacionamento com o meio ambiente natural.

Portanto, é necessário que a comunidade receptora perceba o quanto é importante preservar e conservar o meio ambiente. Uma comunidade consciente estará preparada para receber bem o turista e saberá cobrar dele o respeito para com a localidade e, principalmente, com a natureza.

Diante disso, o ser humano, antes de tudo, deve obter conhecimento sobre o seu próprio habitat, seja ele na zona urbana ou na zona rural, para poder agir de maneira sustentável fazendo com que suas ações não afetem tão negativamente o meio ambiente por meio da geração de impactos resultantes da atividade turística e, assim, suas decisões sejam mais conscientes. 


\section{INSERÇÃO DA EDUCAÇÃO AMBIENTAL NAS ESCOLAS}

A Educação Ambiental é vista como um tipo ou meio de solução para minimizar e prevenir os possíveis e atuais problemas ambientais que atingem o planeta. Daí, a importância deste tipo de educação ambiental ser inserida à educação formal.

A partir da formulação da $\mathrm{Lei}^{4}$ que dispõe sobre a Educação Ambiental, o Brasil tornou-se o pioneiro na América Latina a desenvolver uma Política Nacional específica para a mesma, que futuramente poderá ser inserida a partir dos níveis básicos da educação formal.

Tem-se percebido o agravamento da degradação ambiental, abrindo espaço para discussões sobre o assunto e, consequentemente, tornando o PNEA, Política Nacional de Educação Ambiental (1999), e a Educação Ambiental como componentes essenciais na educação das gerações futuras.

O que se pretende com a proposta pedagógica da educação ambiental no ensino formal é o "saber ambiental" que as pessoas deveriam ter e usá-lo como instrumento de convivência da espécie humana com os demais seres. Entretanto, a Política Nacional de Educação Ambiental no Brasil (1999) não exige que a Educação Ambiental seja inserida nas instituições de ensino, pois as pessoas necessitam perceber que são partes integrantes do meio-ambiente e, assim, corresponsáveis pela sua qualidade. Sobre Educação Ambiental tem-se que a mesma

[...] deve ser trabalhada unificando a teoria com a prática educativa, considerando o cotidiano dos educandos e compreendendo a complexidade das relações entre o ser humano e a natureza como partes de um ambiente integrado e complementar. A deficiência na inserção da EA no ensino formal se apresenta desde as séries iniciais até o nível superior, uma vez que a maioria dos cursos não trabalha a temática, fato que reflete negativamente ante a necessidade de os futuros profissionais contribuírem eficazmente para a preservação e conservação do meio ambiente. A educação, sozinha, não resolve todos os problemas ambientais, nem é suficiente para mudar os rumos do planeta, mas contribui para formar cidadãos mais conscientes, críticos, participativos e responsáveis pelo futuro do planeta. (BRANCO; LINARD; SOUSA, 2011, p. 4).

O desconhecimento do PNEA e o fato da Educação Ambiental não estar inserida, também, tanto na formação de professores como na proposta pedagógica dos planos de aulas desses profissionais, faz com que se perceba a necessidade de melhorar a qualidade de ensino para esses jovens, o que, consequentemente, evitaria os gastos desnecessários destinados a

\footnotetext{
${ }^{4}$ Lei n ${ }^{\circ} 9.795$, de 27 de abril de 1999.
} 
suprirem as lacunas resultantes dos problemas ambientais ocasionados devido o nãoconhecimento sobre Educação Ambiental.

\begin{abstract}
A EA, assim como a educação básica, deve começar em casa e extrapolar os muros; gerar conhecimento global e envolver toda a comunidade. Ela deve ser analisada levando em consideração a ação do homem como sujeito social responsável pelos seus atos. Apesar das tentativas e esforços para introduzir a

EA nos diferentes níveis escolares, esta iniciativa não tem alcançado o êxito desejável, tornando-se, assim, necessárias mudanças na forma de abordagem, isto é, da prática em sala de aula. (BRANCO; LINARD; SOUSA, 2011, p. 4).
\end{abstract}

Apesar da Política Nacional de Educação Ambiental (PNEA) destacar a importância da Educação Ambiental ser inserida tanto nos níveis básicos de educação formal quanto na graduação, os temas ambientais não são debatidos como deveriam.

Diante de todas as informações supracitadas, evidenciou-se ser fundamental a inclusão social das crianças a partir da inserção da educação ambiental nas escolas, não só como ações pontuais, mas que seja realizado acompanhamento contínuo, e divulgação de ações que envolvem esta temática, com a finalidade de difundir, cada vez mais, o pensamento voltado para a sustentabilidade ambiental do planeta.

\title{
7 METODOLOGIA DO PROJETO
}

Inicialmente foram realizados estudos e pesquisas para a elaboração dos materiais utilizados na realização das atividades (palestras, painéis etc.) por meio da orientação da coordenadora do projeto, a professora Kettrin Farias Bem Maracajá, através de realização de reuniões para discussão da viabilidade do projeto que pudesse facilitar a compreensão sobre a relação direta entre a educação ambiental e o turismo.

A partir disso as atividades realizadas tiveram como principal objetivo conscientizar e/ou sensibilizar as pessoas para a questão da importância da preservação e conservação do meio ambiente buscando, na educação ambiental, métodos para desenvolver atividades de menor impacto. Para tanto, procurou-se repassar os conhecimentos de maneira espontânea e simples para os alunos a medida do transcorrer dos fatos.

Posteriormente, foi definido que as atividades seriam realizadas com os alunos respectivos de cada série, devido à faixa etária. Foram realizadas palestras em conjunto com dinâmicas de grupo com foco para a educação ambiental, como "perguntas e respostas", nas 
quais era possível medir os conhecimentos adquiridos na palestra "Água é vida" em que se mostrava aos alunos uma noção da quantidade de água existente no planeta.

As palestras oscilavam entre 35 a 45 minutos de duração, nas quais foram trabalhadas as problemáticas ambientais existentes atualmente no planeta, buscando implantar no públicoalvo medidas que possam alterar suas atitudes com relação ao meio ambiente, tornando-as adeptas a tentarem ajudar o quadro atual do planeta, desenvolvendo medidas básicas sobre educação ambiental, tais como a coleta seletiva de lixo, poluição do ar, poluição das águas, entre outras; além de usar como exemplos de degradação a atual situação da região do Seridó, região do nordeste do Brasil onde se localiza a cidade de Currais Novos, local de realização das palestras, resultante da atividade das cerâmicas em algumas cidades da região, a falta de saneamento básico, a má qualidade da água tanto para uso humano como para uso doméstico, entre outras.

Por fim, sempre eram realizadas dinâmicas a fim de fixar o assunto abordado com as crianças. A dinâmica era de perguntas e respostas com o intuito de obter o índice de aprendizado captado pelos alunos, com relação à atenção e importância dada ao tema abordado, a qual mostrou-se bastante proveitosa já que os alunos presentes não tiveram nenhuma dificuldade em responder as tais questões relacionadas ao assunto abordado.

\section{RESULTADOS E DISCUSSÕES}

De acordo com o que foi estudado e pesquisado durante todo o projeto, as escolas públicas, apesar de desenvolverem projetos paralelos entre si relacionados ao meio ambiente, abordam a questão da preservação e conservação do meio ambiente, fazendo com que os alunos despertem a curiosidade para saber, por exemplo, para onde vai o lixo produzido em suas casas.

Além disso, observou-se que as escolas envolvidas no projeto adotaram a coleta seletiva fazendo com que os alunos realmente conheçam a importância de separar o lixo e qual a finalidade desta ação, bem como a inserção de cartazes educativos expostos nos murais das escolas ao que se refere à questão de jogar lixo no lixo e de evitar o desperdício de energia e água. 
As práticas mais desenvolvidas nas escolas foram: controle de consumo de energia e água; coleta seletiva; porque o lixão e prejudicial à saúde; desertificação; porque é importante não desmatar a vegetação nativa de uma localidade ou região; entre outras ações. Portanto, é importante mencionar que as escolas abordam a questão da educação ambiental em sala de aula principalmente com as crianças, público-alvo deste trabalho, objetivando a conscientização das mesmas para a preservação do meio ambiente, além de ensiná-las a realizar ações que promovam esta prática e ressaltar a importância de cada uma delas.

Partindo dos textos estudados para obtenção do conhecimento especifico do assunto a ser pesquisado, e como foi visto durante a realização de visitas e palestras, as escolas desenvolvem ações de sustentabilidade. Além disso, promovem a educação ambiental e objetivam o desenvolvimento da preservação do meio ambiente de maneira planejada e agregando valor ao reaproveitamento dos recursos e dejetos que, na realidade local do município de Currais Novos, os mesmos são jogados a céu aberto e sem nenhuma consciência para com os possíveis impactos causados no meio ambiente.

Esse trabalho foi desenvolvido com alunos das séries de ensino fundamental I (de $1^{\circ}$ ao $5^{\circ}$ ano) de 11 escolas públicas (estaduais e municipais) do município de Currais Novos (Rio Grande do Norte, Brasil), durante o ano de 2010. As escolas foram visitadas apenas no turno matutino, totalizando 1.312 alunos beneficiados. As escolas visitadas foram: a Escola Estadual Tristão de Barros, Escola Estadual Capitão Mor Galvão, Escola Municipal Nossa Senhora, Escola Estadual Francisco Rosa, Escola Estadual Francisco Leônis, Escola Estadual Castelo Branco, Escola Estadual Professor Salustiano Medeiros, Escola Municipal Ausônio Araújo, Escola Municipal Estér Galvão, Escola Estadual Gilson Firmino, Escola Lions Clube.

O período de realização do projeto "Educação Ambiental e a conscientização da população" teve início no dia 13 de janeiro de 2010 e foi finalizado dia 17 de dezembro de 2010.

Os objetivos do projeto eram: - Estudar, analisar e conscientizar a população sobre a importância da educação ambiental; - Iniciar futuros educadores ambientais; - Despertar na população a importância que a educação ambiental proporciona para todos; - Incentivar a divulgação sobre a educação ambiental em todas as escolas públicas; - Mostrar que o mínimo de educação ambiental ajuda na melhoria das condições de vida da população; - Estudar a educação ambiental como forma de conscientizar as gerações futuras para que exista uma maior preservação ambiental. 
O Projeto obedeceu a um processo de rotatividade, de forma que, ao final, todas as escolas tivessem tomado conhecimento da importância da conscientização ambiental. No qual esse conhecimento foi levado aos alunos através de: Painel biobibliográfico; Palestras; Brincadeiras de conscientização ambiental; Debates. Todas essas atividades contribuíram para a formação intelectual e estética dos alunos e também para que a comunidade escolar envolvida possa desfrutar desse intercâmbio formado entre o CERES - Campus de Currais Novos e as Escolas Estaduais e Municipais da cidade de Currais Novos.

\section{CONSIDERAÇÕES}

As escolas visitadas durante a realização do trabalho apresentaram ações e políticas de educação ambiental. Salientando que a educação ambiental é o fator determinante para o desenvolvimento de alternativas para a busca de preservação e conservação do meio ambiente.

Neste caso, é imprescindível mencionar que as escolas públicas (municipais e estaduais) do município de Currais Novos, se preocupam notadamente com o desenvolvimento sustentável, principalmente voltado para a realidade local, além de buscar meios para fins de preservação e conservação do meio ambiente, como foi visto em pesquisas referentes ao assunto e nas visitas feitas as mesmas, além da realização das palestras.

O projeto "Educação Ambiental e a conscientização da população" possuiu significância cultural, social e política, ao que diz respeito a mudanças de hábitos prejudiciais ao meio ambiente que venham a influenciar diretamente a vida dos seres vivos no planeta, visto a utilização dos conceitos de educação ambiental.

Os objetivos de estudar, analisar e conscientizar a população sobre a importância da educação ambiental nos dias atuais, despertar na população a importância que a educação ambiental trás para todos, incentivar a divulgação sobre a educação ambiental em escolas públicas mostrando que o mínimo de educação ambiental feita ajuda na melhora das condições de vida da população e estudar a educação ambiental como forma de conscientização das gerações futuras para que exista uma maior preservação ambiental foram atendidos e as expectativas em relação a aceitação dos ensinamentos por parte dos alunos 
foram superadas, pois os alunos participaram ativamente nas discussões, realizando observações cotidianas e perguntando o que achavam que cabia.

Às perguntas de interação que mais se destacaram na realização das dinâmicas de perguntas e respostas foram: O que vocês entendem por Educação Ambiental? O que vocês fazem para economizar energia? Vocês plantam em casa? Economizam água? O que as escolas fazem para ajudar os alunos a se conscientizarem? Vocês jogam lixo nas ruas, escolas ou rios? O que vão fazer para ajudar o meio ambiente? O que aprenderam com a palestra?

O projeto despertou nas crianças a consciência de que se deve preservar e conservar o meio ambiente com pequenas ações: jogar lixo no lixo; evitar deixar luzes acesas e carregadores em tomadas sem necessidade; evitar jogar lixo para fora de veículos; não poluir escolas, casas e ruas; divulgar o aprendido em sala de aula com a palestra. O que significa dizer que o projeto possui caráter multiplicador da informação preocupada com o meio ambiente e a vida existente nele.

Portanto, levando-se em consideração tudo o que foi vivido com a realização do projeto, é possível concluir que os alunos realmente fixaram a importância de preservar o planeta e que, algumas medidas, podem ser feitas dentro das suas próprias casas, visando sempre a sustentabilidade e a conscientização para fins de preservação dos recursos naturais e do próprio planeta.

\section{REFERÊNCIAS}

ANDRADE, J. V. de. Turismo: fundamentos e dimensões. São Paulo: Ática, 1992.

BENI, M. C. Análise estrutural do turismo. 12. ed. rev. e atual. São Paulo: SENAC São Paulo, 2007.

BRANCO, A. F. V. C.; LINARD, Z. U. S. de A.; SOUSA, A. C. B. de. Educação para o desenvolvimento sustentável e educação ambiental. Fortaleza/CE, v. 5, n. 1, p. 28 25-31, mar. 2011.

BRASIL. LEI de Diretrizes e Bases da Educação - No 9394 de dezembro de 1996.

- Secretaria de Educação Fundamental. Parâmetros Curriculares Nacionais. Brasília, MEC/SEF, 1998. 
Ministério da Educação e Cultura, MEC - Coordenação de educação Infantil DPEIEF/SEB - Revista CRIANÇA - do professor de educação infantil. Brasília, DF, n. 42, dez./2005.

CINTRA, G. A. R. Educação ambiental para um turismo responsável: um estudo da relação geografia, turismo e meio ambiente. In: $1^{\circ}$ Simpósio de Pós Graduação em Geografia do Estado de São Paulo - SIMPGEO/SP, Rio Claro, 2008.

DIAS, G. F. Educação ambiental: princípios e práticas. 8. ed. São Paulo: Gaia, 2003.

GOULD, K. A. Classe social, justiça ambiental e conflito político. In: ACSELRAD, H.; HERCULANO, S.; PÁDUA, J. A. (Org.). Justiça ambiental e cidadania. Rio de Janeiro: Relume Dumará, 2004.

NEIMAN, Z; RABINOVICI, R. O cerrado como instrumento para educação ambiental em atividades de ecoturismo. In: NEIMAN, Z. (Org.). Meio ambiente, educação ambiental e ecoturismo. São Paulo: Manole, 2002.

RUSCHMANN, D. V. de M. Turismo e planejamento sustentável. São Paulo: Papirus, 1997.

TOMAZELLO, M. G. C.; FERREIRA, T. R. das C. Educação ambiental: que critérios adotar para avaliar a adequação pedagógica de seus projetos? Revista Ciência e Educação, São Paulo. V. 7, n. 2, p. $199-207,2001$.

UNESCO-UNEP. International strategy for action in the field of environmental education and training for the 1990s. Paris: UNESCO e Nairobi. 1987.

Recebido em: 11-09-2011.

Aprovado em: 11-10-2011. 